\title{
Subsurface Drip Irrigation Emitter Spacing EFFECTS ON SOIL WATER REDISTRIBUTION, Corn Yield, ANd Water Productivity
}

\author{
G. P. Arbat，F. R. Lamm，A. A. Abou Kheira
}

\begin{abstract}
Emitter spacings of 0.3 to $0.6 \mathrm{~m}$ are commonly used for subsurface drip irrigation (SDI) of corn on the deep, silt loam soils of the U.S. Great Plains. Subsurface drip irrigation emitter spacings of 0.3, 0.6, 0.9 and $1.2 \mathrm{~m}$ were examined for the resulting differences in soil water redistribution, corn grain yield, yield components, seasonal water use, and water productivity in a 4-year field study (2005 through 2008) at the Kansas State University Northwest Research-Extension Center, Colby, Kansas.

The results indicate that there is increased preferential water movement along the dripline (parallel) as compared to perpendicular to the dripline and that this phenomenon partially compensates for wider emitter spacings in terms of soil water redistribution. Corn yield and water productivity (WP) were not significantly affected by the emitter spacing with application of a full irrigation regime.
\end{abstract}

Keywords. Microirrigation, Irrigation design, Soil water movement, Water use efficiency.

$\mathrm{D}$ eclining groundwater in some parts of the Central Great Plains (United States) is pressing irrigators to look for more efficient methods of irrigation than the traditional center-pivot sprinkler and furrow irrigation. Subsurface drip irrigation (SDI) can be a viable alternative when water is limited or when the irrigation capacity is insufficient with traditional methods. Lamm and Trooien (2003) reported that SDI can reduce irrigation water use for corn production by $35 \%$ to $55 \%$ compared with traditional irrigation methods. Camp (1998) indicated that yield for over 30 crops was greater or equal using SDI than that obtained with other irrigation methods and in most of the cases required less water. Nevertheless, the irrigation system itself does not guarantee all the potential benefits; an adequate design and management are also required.

Different methods have been proposed to design SDI systems. Battam et al. (2003) described a detailed field method to derive design factors for SDI that involved monitoring within an excavated soil pit the advancement of the wetting front over time from a subsurface emitter. Schwartzman and Zur (1986) presented a procedure, based

Submitted for review in October 2009 as manuscript number SW 8252 approved for publication by the Soil \& Water Division of ASABE in February 2010. Presented at the 2009 ASABE Annual Meeting as Paper No. 096578.

Mention of trade names is for informational purposes only and does not constitute endorsement by the authors or by the institutions they serve.

The authors are Gerard P. Arbat, Assistant Professor, Department of Chemical and Agricultural Engineering and Technology, University of Girona, Girona Spain; Freddie R. Lamm, ASABE Member Engineer, Professor, Research Irrigation Engineer, Northwest Research Extension Center, Kansas State University, Colby, Kansas; and Abdrabbo A. Abou Kheira, Assistant Professor, Water Management Research Institute, National Water Research Center, Delta Barrage, Egypt. Corresponding author: Freddie R. Lamm, Northwest Research Extension Center, Kansas State University, 105 Experiment Farm Road, Colby, KS 67701; phone: 785-462-6281; fax 785-462-2315; e-mail: flamm@ksu.edu. on empirical equations, for computing the optimal emitter spacing to determine maximum width and depth of the wetted soil volume and on the cost of the lateral for surface drip irrigation (DI). Similar equations to estimate maximum width and depth of the wetted soil under SDI were developed by Singh et al. (2006). Soil water redistribution and flow models can be used to compute a detailed soil water distribution under SDI (Warrick and Or, 2007), but for a reliable application, the knowledge of the specific soil hydraulic characteristics of the site is required (Thorburn, 2003). This fact, combined with the technical skills needed to apply soil water flow models with confidence, have limited their use for irrigation design.

Numerous experimental studies have been conducted to evaluate various design factors for SDI systems for corn production on deep silt loam soils of the Central Great Plains. Dripline depths ranging from 0.2 to $0.6 \mathrm{~m}$ were found to be acceptable for corn production with no significant differences in water productivity (WP) and only slight reductions in corn grain yield for the deeper 0.4 and 0.6 dripline depths (Lamm and Trooien, 2005). As a general rule, SDI dripline spacing is a multiple of the crop row spacing, whereas emitter spacing is usually related to the plant spacings within the row. The goal of all SDI designs should be to provide the crop with equal or nearly equal opportunity to the applied water. A dripline spacing of $1.5 \mathrm{~m}$ for corn rows spaced at $0.75 \mathrm{~m}$ produced the largest grain yield, greatest water productivity (WP), and smallest year to year grain yield variation (Lamm et al., 1997). In the U.S. Great Plains region, emitter spacing along the dripline is usually 0.3 or $0.6 \mathrm{~m}$ for corn production and is primarily influenced more by the products being marketed than by design needs (Lamm and Trooien, 2003 and 2005; Lamm and Camp, 2007).

Increasing the emitter spacing can provide several advantages: (1) to allow larger emitter passageways less subject to clogging; (2) to allow for economical use of more 
expensive emitters, and (3) to allow longer length of run or increased zone size by decreasing the dripline nominal flowrate per unit of length (Lamm and Camp, 2007). However, excessive emitter spacing must be avoided in order to prevent inadequate water distribution within the root zone. Another disadvantage of increased emitter spacing is the compounding of the water redistribution problem when emitters become clogged and the result is inadequately irrigated plants (Lamm and Camp, 2007). The design process should carefully match emitter discharge and emitter spacing to the soil hydraulic characteristics in order to avoid problems such as backpressure and water surfacing that can occur with improper design. These problems can reduce irrigation uniformity (Shani et al., 1996; Warrick and Shani, 1996; Lazarovitch et al., 2005) and can exacerbate soil water redistribution problems (Shani et. al., 1996; Battam et al., 2002). Manufacturers readily market driplines with emitter spacings ranging from 0.10 to $0.76 \mathrm{~m}$ (Schwankl and Hanson, 2007), but other emitter spacings can be manufactured on demand.

Seginer (1979), using a conceptual model, pointed out the importance of the extent of the rooting system in the design process, showing that effective uniformity experienced by the crop can be very high, while the detailed actual soil water distribution in microirrigation can be quite nonuniform.

Emitter spacing is a system design characteristic and should be selected taking into account the soil water properties of the site, the specific rooting system of the crop, and the climatic characteristics as it affects the extent to which the crop depends on irrigation. The purpose of this paper is to discuss the effect of different emitter spacings (nominal values of $0.3,0.6,0.9$ and $1.2 \mathrm{~m}$ ) on soil water redistribution, corn yield and water productivity in deep silt loam soils of semi-arid western Kansas.

\section{Procedures}

Field studies were conducted at Kansas State University Northwest Research-Extension Center at Colby, Kansas, during the period 2005-2008, on a deep, well-drained, loessial Keith silt loam soil (Aridic Argiustoll) described in more detail by Bidwell et al. (1980). The 2.4-m soil profile holds approximately $445 \mathrm{~mm}$ of available water at field capacity, which corresponds to a volumetric soil water content of $0.37 \mathrm{~cm}^{3} / \mathrm{cm}^{3}$. The region has an average annual precipitation of $481 \mathrm{~mm}$ with a summer pattern resulting in an average corn cropping season precipitation of $299 \mathrm{~mm}$. The average seasonal total crop evapotranspiration (ETc) for corn is $586 \mathrm{~mm}$. The latitude is $39.39^{\circ}$ north and the longitude is $101.07^{\circ}$ west with an elevation of $963 \mathrm{~m}$ above sea level.

The study consisted of a randomized complete block design of three replications of four different emitter spacing treatments $(0.30,0.61,0.91$, and $1.22 \mathrm{~m})$. Nominal emitter spacings values of $0.3,0.6,0.9$, and $1.2 \mathrm{~m}$ will be used in the remainder of the discussion. Each plot was approximately $9 \mathrm{~m}$ wide and $25 \mathrm{~m}$ long, with six driplines spaced at $1.52 \mathrm{~m}$ running west to east. Each plot (six driplines) had a common submain at the inlet side of the plot and a common flushline and flush valve at the distal end of the plot. Buffer distances areas of approximately $5 \mathrm{~m}$ were provided on the North and South edges of the study area to reduce environmental influences from outside the study area. The SDI system was installed in August 2005 and consisted of 22-mm inside diameter (I.D.) thin-wall driplines with welded-on emitters (Netafim 875 Typhoon) with a nominal emitter discharge of $0.68 \mathrm{~L} / \mathrm{h}$ at a design pressure of $69 \mathrm{kPa}$. Since nominal emitter flow rate was constant at $0.68 \mathrm{~L} / \mathrm{h}$, the resultant dripline flowrates were approximately 2.26, 1.12, 0.75, and $0.56 \mathrm{~L} / \mathrm{h}-\mathrm{m}$ for the $0.3-, 0.6-, 0.9-$, and $1.2-\mathrm{m}$ emitter spacings, respectively. The system was installed at an approximate depth of $0.33 \mathrm{~m}$ using a tractor-mounted shank-type injector (three shanks spaced $1.52 \mathrm{~m}$ apart). Care was used in the installation process to insure that the emitter location for each of the six driplines within a plot started at the same perpendicular distance from the control box at the submain. Prior to backfilling the trenches at the inlet of driplines (submain trench), the location of the first emitter was determined and carefully measured with respect to the fixed control box at the beginning of each plot. These procedures allowed for subsequent location of emitter positions within the field for the four different emitter spacings that was necessary for the various soil water sampling and crop yield measurement procedures during the course of the study. Similarly, the third dripline from the south which was aligned with the submain control box and the flushline flush valve was carefully marked so that measurements perpendicular to the dripline could be determined.

During the summer of 2005, prior to the SDI installation, soil water was extracted by grain sorghum, which was destroyed prior to maturity in late August by flail chopping. After the crop destruction, the dry surface soil (upper $0.10-0.12 \mathrm{~m}$ ) was thoroughly disked and was subsequently leveled and re-firmed using a spring tooth packer. After dripline installation, the soil surface was again leveled and firmed using a spring tooth packer.

Irrigation amounts were metered separately onto each plot using commercial municipal-grade flow accumulators with an accuracy of $\pm 1.5 \%$. Irrigation time was different for each treatment because of the different emitter spacings (i.e., it took four times as long to apply an irrigation event for the 1.2-m emitter spacing than for the $0.3-\mathrm{m}$ emitter spacing). For two special non-cropped irrigation events (September 2005 and May 2006), the treatment irrigation event start times were staggered over time so that all treatments finished irrigation on the same approximate date and time. This technique allowed for soil water sampling after a fixed period following the irrigation event rather than contending with deep percolation for longer nonirrigation periods for the smaller emitter spacings. However, it can be noted that some deep percolation would occur for the greater emitter spacings during their longer irrigation event times.

Non-cropped single irrigation events with a $25-\mathrm{mm}$ total amount were scheduled in early September 2005 and in May 2006. These special irrigation events were started on 2 September through completion on 5 September 2005 and on 2-5 May 2006. The study protocol was to measure gravimetric soil water content in perpendicular and parallel distances from the emitter before and after the irrigation event.

Soil samples were extracted in 76- $\mathrm{mm}$ increments to a depth of $1.2 \mathrm{~m}$ using a tractor-mounted hydraulic-coring machine with a stainless steel coring tube of $38 \mathrm{~mm}$ I.D. Soil samples perpendicular to the dripline were extracted at distances of $15,31,46$, and $61 \mathrm{~cm}$ from the emitter with 
accuracy as close (approximately 1.5 to $2 \mathrm{~cm}$ ) as practical controlled by a plywood template with coring tube holes cut at the appropriate distance. This square template was centered at the emitter location and aligned parallel to the dripline direction using the predetermined dripline and emitter locations discussed earlier. The samples in the direction parallel to the dripline were at distances of 15,31 , 46 , and $61 \mathrm{~cm}$ from the emitter location or until the midpoint between emitters was reached. In the parallel direction, samples were cored at a $10-\mathrm{cm}$ perpendicular distance from the dripline to avoid damaging or severing the dripline. Soil sampling occurred on 31 August 2005, prior to the irrigation event of 2-5 September, with subsequent soil sampling on 8 September. The later date was as close as practical to the end of the irrigation event for removing wet soil cores from the machine. Soil samples were also taken on 2 May 2006, prior to the irrigation event beginning on that day, and later on 8 May at the earliest possible date following completion of the irrigation on 5 May. There were no reasons for soil water conditions to be affected spatially (parallel or perpendicular to the dripline) for the initial 31 August 2005 sampling date, so only one set of vertical samplings were obtained from each plot. Soil samples were weighed while wet and dried in a forced-air oven at approximately $105^{\circ} \mathrm{C}$ until there was no further change in mass for gravimetric water content determination.

After the soil sampling in the fall of 2005, the study area was planted to wheat and irrigated with sprinkler irrigation applying approximately $250 \mathrm{~mm}$ of water. This large sprinkler irrigation amount was applied with the intent of equalizing soil water differences and to consolidate the soil profile. A hypothesis was that after soil consolidation any preferential flow along the dripline that might exist after initial SDI system installation might be removed or become negligible. The wheat was planted to extract soil water and it was destroyed and removed from the field area in late April 2006 prior to soil sampling and irrigation commencing on 2 May 2006.

Soil cores for bulk density determination were obtained on 21 September 2005 (diameter $38 \mathrm{~mm}$, length $152 \mathrm{~mm}$ centered about the 230 to 380 profile depth) and on 8 May 2006 (diameter $38 \mathrm{~mm}$, length $229 \mathrm{~mm}$ centered about the 230 to 380 profile depth) to examine differences from disturbed and undisturbed soil at 0.10 and $0.46 \mathrm{~m}$ perpendicular distances from the dripline. Two samples from each of the $0.3-\mathrm{m}$ spacing treatment plots were obtained for each of the dates and were dried in a forced-air oven at $103^{\circ} \mathrm{C}$ until there was no further change in mass for bulk density water content determination.

A corn hybrid of approximately 110-day relative maturity (DCK60-18) was planted in 76-cm spaced rows at a seeding rate of approximately 90,000 seeds/ha on 20 April 2006 and 2 May 2007, and 29 April 2008, so that each dripline was centered between two corn rows, as it is common practice in western Kansas (Lamm and Trooien, 2003). The study area was broadcast fertilized with $225 \mathrm{~kg} / \mathrm{ha}$ of $\mathrm{N}$ prior to planting and an additional $32 \mathrm{~kg} / \mathrm{ha}$ of $\mathrm{N}$ (Urea-Ammonium-Nitrate $32-0-0$ ) and $50 \mathrm{~kg} / \mathrm{ha}$ of $\mathrm{P}_{2} \mathrm{O}_{5}$ (Ammonium Superphosphate 10-34-0) was applied during a banding operation at planting. Standard cultural practices for the region for herbicides and insecticides were used in corn production.

The corn was fully irrigated with irrigation scheduled as needed with a weather-based water budget. Irrigation amounts of $50 \mathrm{~mm}$ were applied whenever the calculated soil water deficit reached a level in excess of $50 \mathrm{~mm}$. These are rather large irrigation events for microirrigation but this amount was chosen because the study area was manually controlled in 2006 and this procedure minimized odd and inopportune timing of manual termination of the events. The irrigation season was terminated when the kernel starch line had reached about two-thirds of the distance down the corn kernel. The weather-based water budget was constructed using data collected from a NOAA weather station located approximately $800 \mathrm{~m}$ northeast of the study site. The reference evapotranspiration (ETr) was calculated using a modified Penman combination equation similar to the procedures outlined by Kincaid and Heermann (1974). The specifics of the ETr calculations used in this study are fully described by Lamm et al. (1987). A two-year (2005 and 2006) comparison using weather data from Colby, Kansas of this estimation method to the ASCE standardized reference evapotranspiration equation, which is based on FAO-56 (Allen et al.,1998), indicates that the modified-Penman values are approximately $1.5 \%$ to $2.8 \%$ smaller. This was well within the accuracy of the resultant scheduling and irrigation application procedures. Basal Crop coefficients (Kc) were generated with equations developed by Kincaid and Heermann (1974) based on work by Jensen (1969) and Jensen et al. (1970, 1971). The crop coefficients were calculated for the area by assuming 70 days from emergence to full canopy for corn with physiological maturity at 130 days. This method of calculating ETc as the product of Kc and ETr has been acceptable in past studies at Colby (Lamm and Rogers, 1983, 1985). In constructing the irrigation schedules, no attempt was made to modify ETc with respect to soil evaporation losses or soil water availability as outlined by Kincaid and Heermann (1974). Alfalfa-based ETr is considered to give better estimates than short-grass ETo in this region (Howell, 2007).

Volumetric soil water content was measured weekly or biweekly during each of the three corn seasons with a neutron probe in $0.3-\mathrm{m}$ increments to a depth of $2.4 \mathrm{~m}$ at the corn row (0.38 $\mathrm{m}$ perpendicular from the dripline) at the emitter location and one-halfway between the emitters. These data were used to determine soil water with time during the season and to determine overall crop water use. Seasonal water use was calculated as the sum of irrigation, precipitation, and the change in soil water in the 2.4-m soil profile between the initial soil water sampling (near crop emergence) and the final soil water sampling (near physiological maturity). Water productivity (WP) was calculated as corn grain yield (15.5\% wet-basis moisture content) divided by total crop water use.

Corn production data collected during the growing season included irrigation and precipitation amounts, weather data, grain yield, and yield components (plant density, ears/plant, kernels/ear, kernel mass). Corn grain yields and yield components were determined by hand harvesting individual ears in an approximately 6-m length with reference to a starting position at a SDI emitter from a center row of the 9-m wide plot. Data was collected from every single ear but only the plot average data will be reported in this paper. Ear length and girth in terms of rows were also determined from the individual ears. The harvesting and final soil water data were collected at physiological maturity and grain yields were corrected to $15.5 \%$ wet-basis moisture content. 
The corn yield and yield component data, volumetric soil water contents, crop water use, and water productivity for the different emitter spacings were analyzed using the Proc ANOVA (Analysis of Variance) procedure from the SAS Institute, (Cary, N.C.). Means were separated using a LSD test with a significance level of $\mathrm{P}<0.05$. Similarly, the ANOVA procedure and LSD test were used to analyze the effect of the sampling direction from the dripline (parallel or perpendicular) on the change in gravimetric soil water contents for the two non-cropped irrigation events. In the case of sampling direction, there were equal numbers of samples for a given emitter spacing. However, for the different emitter spacings there would be unequal numbers of samples, so the Proc GLM (General Linear Models) procedure from SAS was used to analyze differences in gravimetric soil water content changes among the different emitter spacings.

\section{Results AND Discussion \\ SOIL WATER REDistribution Following Non-CROPPED IRRIGATION EVENTS}

Soil water content was numerically greater after the initial non-cropped irrigation event (2-5 Sept. 2005) in distances parallel to the dripline than for the perpendicular direction for all the emitter spacing treatments, suggesting that there was increased preferential water flow along the dripline [selected data for 0.3- (fig. 1) and 1.2-m emitter spacings (figs. 2 and 3)]. The greater soil water content in the parallel direction to the dripline may have resulted from the major soil disruption of the dripline shank during installation, saturated flow along the flexible dripline during irrigation and after shutdown, overlapping of the wetting fronts for the consecutive emitters or maybe a combination of the above-mentioned effects. The greater soil water content in the direction parallel to the dripline persisted into the next spring (8 May 2006) with a special non-cropped irrigation event redistribution [selected data for 0.3 - (fig. 1) and 1.2-m emitter spacings (figs. 2 and 3)]. This increased soil water movement along the dripline occurred even though there had been a large $250-\mathrm{mm}$ sprinkler irrigation event conducted on the study area in the fall of 2005 that should have partially reconsolidated the soil profile.

The average gravimetric soil water content change between the pre- and post-irrigation soil sampling dates was determined for both the September 2005 and May 2006 noncropped irrigation events. Taking into account the average change in total soil water from all sampling depths and considering the same number of positions for each lateral orientation, there was greater increase in gravimetric soil water content in the parallel direction to the dripline than for the perpendicular direction (table 1) with statistically significant increases for the 0.9- and 1.2-m emitter spacings in 2005 and for the $0.9-\mathrm{m}$ emitter spacing in 2006. A statistical analysis of these data with respect to differences between emitter treatments was not appropriate due to the large differences in the number of sampling locations required to represent each treatment.

\section{SoIL Bulk Density in the Vicinity of The Dripline}

The soil bulk density in the vicinity of the dripline was measured at the 23- to $38-\mathrm{cm}$ depth to examine the disruption
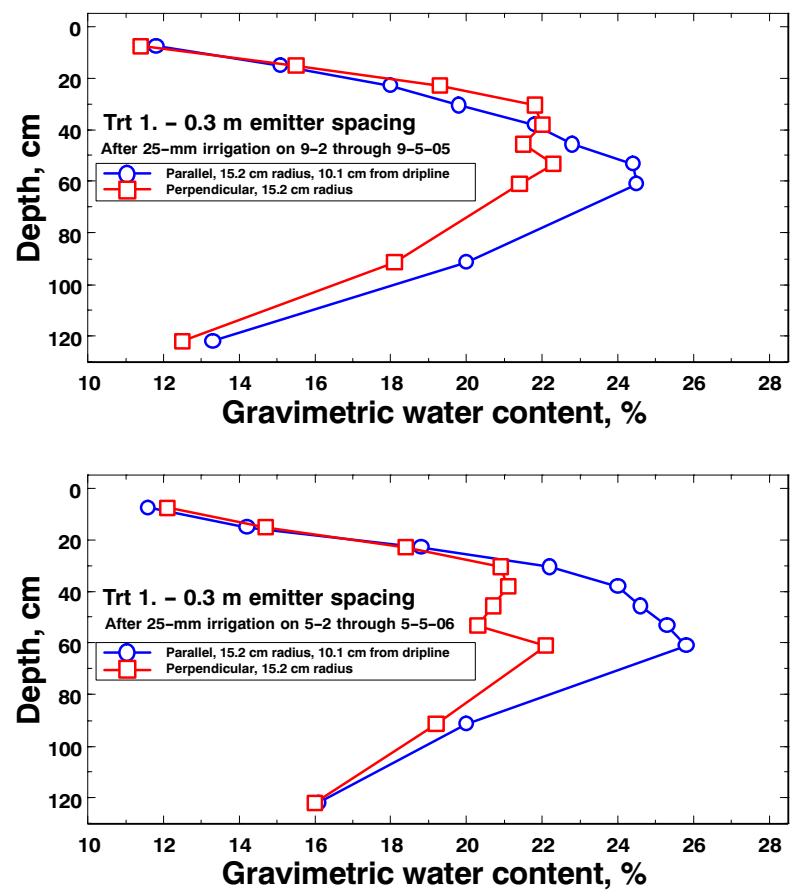

Figure 1. Mean gravimetric soil water contents at a radius of $15.2 \mathrm{~cm}$ from the dripline for the parallel and perpendicular directions for the $0.3 \mathrm{~m}$ of emitter spacing treatment on 8 September 2005 and 8 May 2006 following non-cropped $25-\mathrm{mm}$ irrigation events.
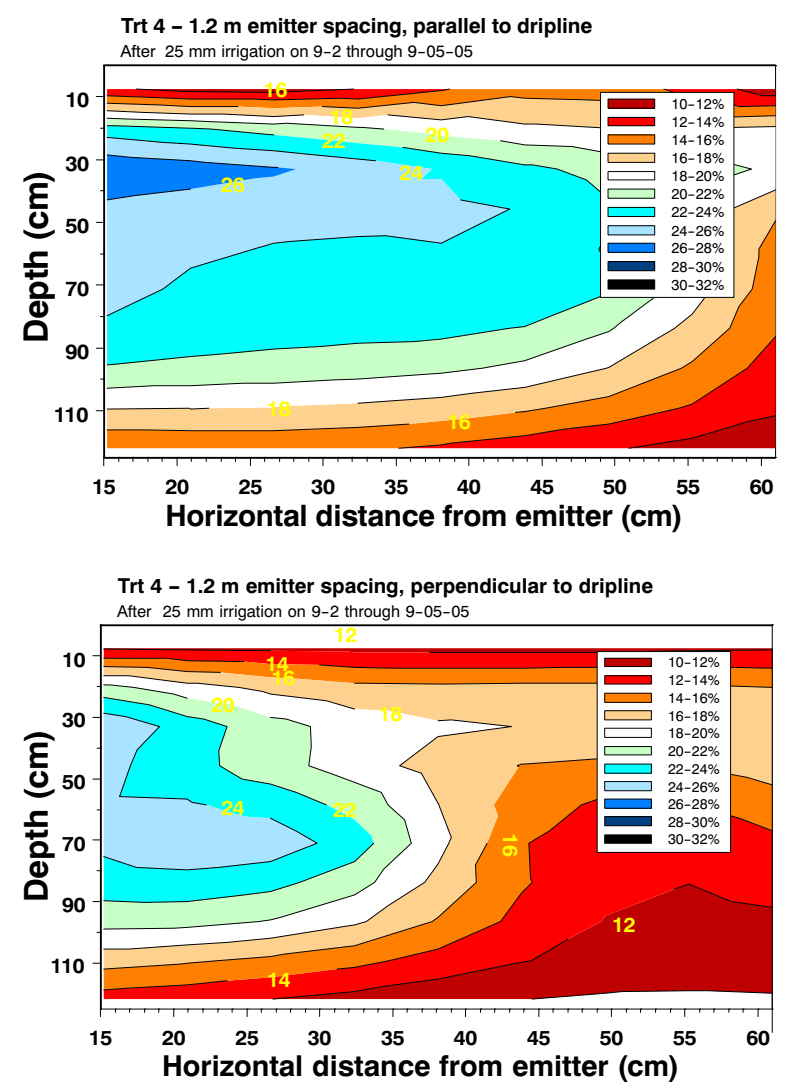

Figure 2. Mean gravimetric soil water contents for the $1.2-\mathrm{m}$ emitter spacing in the parallel and perpendicular directions to the dripline on 8 September following a non-cropped $25-\mathrm{mm}$ irrigation event that occurred from 2-5 September 2005. 

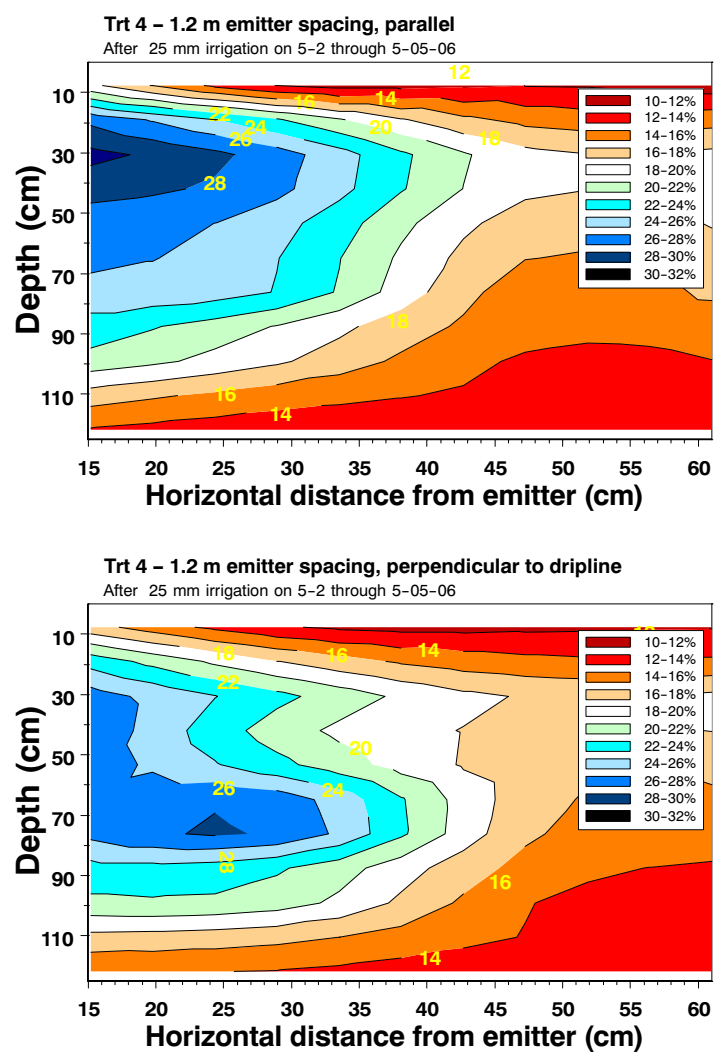

Figure 3. Mean gravimetric soil water contents for the 1.2-m emitter spacing in the parallel and perpendicular directions to the dripline on 8 May following a non-cropped 25-mm irrigation event that occurred from 2-5 May 2006.

caused by the SDI installation of driplines at the $0.33-\mathrm{m}$ depth. Soil samples were taken at a perpendicular distance of $10 \mathrm{~cm}$ from the dripline (the closest practical distance to avoid damaging or severing the driplines) and at a distance of $46 \mathrm{~cm}$. There was a significantly greater bulk density at the 46-cm distance in 2005, but not in 2006 (table 2). The smaller

Table 1. Average gravimetric soil water content change for the parallel and perpendicular directions from the dripline measured

3 days after noncropped $25-\mathrm{mm}$ irrigation events on 2-5 September 2005 and on 2-5 May 2006.

\begin{tabular}{ccc}
\hline Emitter Spacing $(\mathrm{m})^{[\mathrm{a}]}$ & Parallel & Perpendicula \\
\hline Irrigation Event Conducted on 2-5 September 2005 & \\
0.3 & 0.0087 & 0.0029 \\
0.6 & 0.0185 & -0.0015 \\
0.9 & $0.0256 \mathrm{a}$ & $0.0002 \mathrm{~b}$ \\
1.2 & $0.0257 \mathrm{a}$ & $-0.0002 \mathrm{~b}$
\end{tabular}

Irrigation Event Conducted on 2-5 May 2006

$\begin{array}{ccc}0.3 & 0.0336 & 0.0215 \\ 0.6 & 0.0299 & 0.0234 \\ 0.9 & 0.0404 \mathrm{a} & 0.0233 \mathrm{~b} \\ 1.2 & 0.0350 & 0.0290\end{array}$

[a] Means for changes in gravimetric soil content for parallel and perpendicular directions followed by different letters are significantly different at the $\mathrm{P}<0.05$ probability level. For each emitter spacing treatment, the same number of observations were used to compute the mean value for each direction.

Note: A statistical analysis across emitter spacing treatments is not appropriate for these data due to the large difference in numbers of sampling locations.
Table 2. Soil bulk density measured at perpendicular distances of 10 and $46 \mathrm{~cm}$ from the dripline at a depth of $23-38 \mathrm{~cm}$ in September 2005 and May 2006.

\begin{tabular}{ccc}
\hline & \multicolumn{2}{c}{ Bulk Density $\left(\mathrm{g} / \mathrm{cm}^{3}\right)^{[\mathrm{a}]}$} \\
\cline { 2 - 3 } Year & $10 \mathrm{~cm}$ & $46 \mathrm{~cm}$ \\
\hline 2005 & $1.33 \mathrm{~b}$ & $1.43 \mathrm{a}$ \\
2006 & 1.26 & 1.32 \\
Mean & 1.29 & 1.37 \\
\hline
\end{tabular}

[a] Bulk density means with different letters are significantly different at the $\mathrm{P}<0.05$ probability level.

values near the dripline may be indicating the disruption caused by the installation shank and may also suggest even more disruption closer to the dripline introducing voids conducive to preferential flow. However, this bulk density sampling was minimal and the differences may not be very representative of the study area.

\section{WEATHER CONDITIONS AND IRRIGATION REQUIREMENTS DURING The Three Crop Seasons}

The calculated corn evapotranspiration was 598, 501, and $561 \mathrm{~mm}$ for 2006, 2007, and 2008, respectively, as compared to the long-term average of $586 \mathrm{~mm}(1972-2008)$ for the 120-day period 15 May through 11 September (fig. 4). Precipitation during the corn growing period was 290, 219, and $341 \mathrm{~mm}$ for 2006, 2007, and 2008, respectively, as compared to the long-term average of $300 \mathrm{~mm}$ (fig. 4). The greater evapotranspiration in 2006 coupled with less than average precipitation until very late in the cropping period resulted in the greatest irrigation need for any of the three seasons at $356 \mathrm{~mm}$. Although growing season precipitation was actually the least in 2007, mild temperatures and light winds decreased evapotranspiration enough that the irrigation need was only $254 \mathrm{~mm}$. In 2008, the first one-half of the season before corn anthesis (silking and pollination) was very dry but the last one-half the season had abundant and timely rainfall resulting in a total irrigation need of $328 \mathrm{~mm}$.

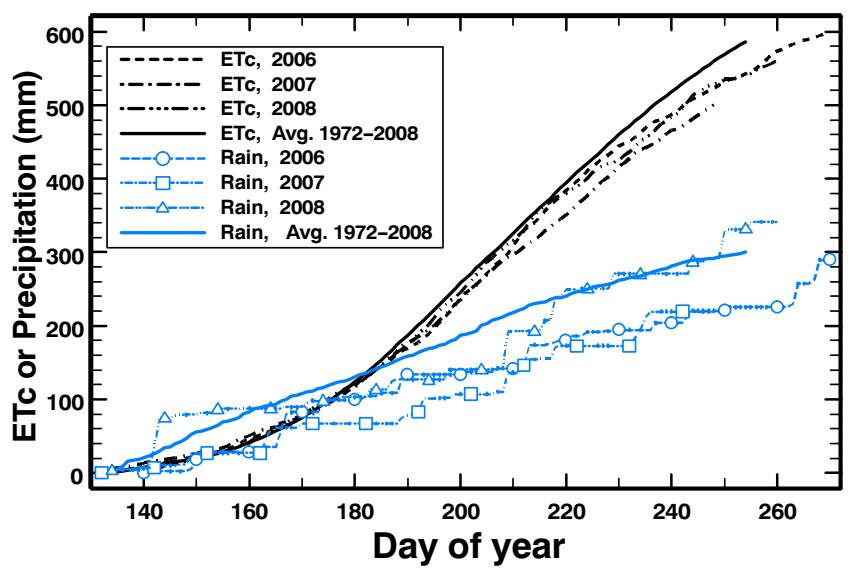

Figure 4. Calculated corn evapotranspiration and precipitation during the three growing seasons as compared to the long-term (1972-2008) 120-day (15 May through 11 Sept.) average values. Note: The 2006 through 2008 values are expressed for the actual crop growing period (emergence to physiological maturity) rather than for 15 May through 11 September (DOY 135 to 254). 
Effect of Emitter Spacing on Soll Water Content

The volumetric water content in the $2.4-\mathrm{m}$ soil profile was maintained at greater than $0.19 \mathrm{~cm}^{3} / \mathrm{cm}^{3}$ throughout 2006 and 2008 (figs. 5 and 7, respectively) and greater than $0.22 \mathrm{~cm}^{3} / \mathrm{cm}^{3}$ throughout 2007 (fig. 6) for all emitter spacing treatments and also for both sampling locations (adjacent to emitter and one-half spacing between emitters). These soil water levels would not be anticipated to impose much restriction on crop development or crop yield (Lamm and Abou Kheira, 2009). The greatest differences between sampling locations for the different emitter spacings occurred in 2006 when for a significant portion of the season the differences in volumetric water content was as much as 0.02 greater for the sampling location adjacent to the emitter for the wider 0.9 and 1.2 emitter spacings (fig. 5). The crop year 2006 was the driest of all three years (greatest evapotranspiration and relatively low precipitation until late in season) and it is not surprising that it would have the greatest differences among sampling locations. There were generally little or no differences between sampling locations for the smaller emitter spacings $(0.3$ and $0.6 \mathrm{~m})$ in any of the three years (figs. 5-7). It should be pointed out that although the region is semi-arid, it does have a summer pattern precipitation that would help to reduce soil water content differences related to SDI with different emitter spacings. This was particularly the case in 2008 where soil water actually increased during the latter portion of the season (fig. 7).

Additionally, the soil in this study has good water holding capacity (field capacity of $0.37 \mathrm{~cm}^{3} / \mathrm{cm}^{3}$ ) which will reduce deep percolation and retain more water within the $2.4-\mathrm{m}$ soil profile. These two factors (summer-pattern precipitation and soil water holding capacity) would be important buffering systems for the wider emitter spacings that would not likely occur in winter-pattern precipitation (Mediterranean) climates or for coarser, sandier soils.

For brevity, the statistically significant differences for the mean volumetric water contents on the different sampling dates within the three cropping seasons (2006 through 2008)

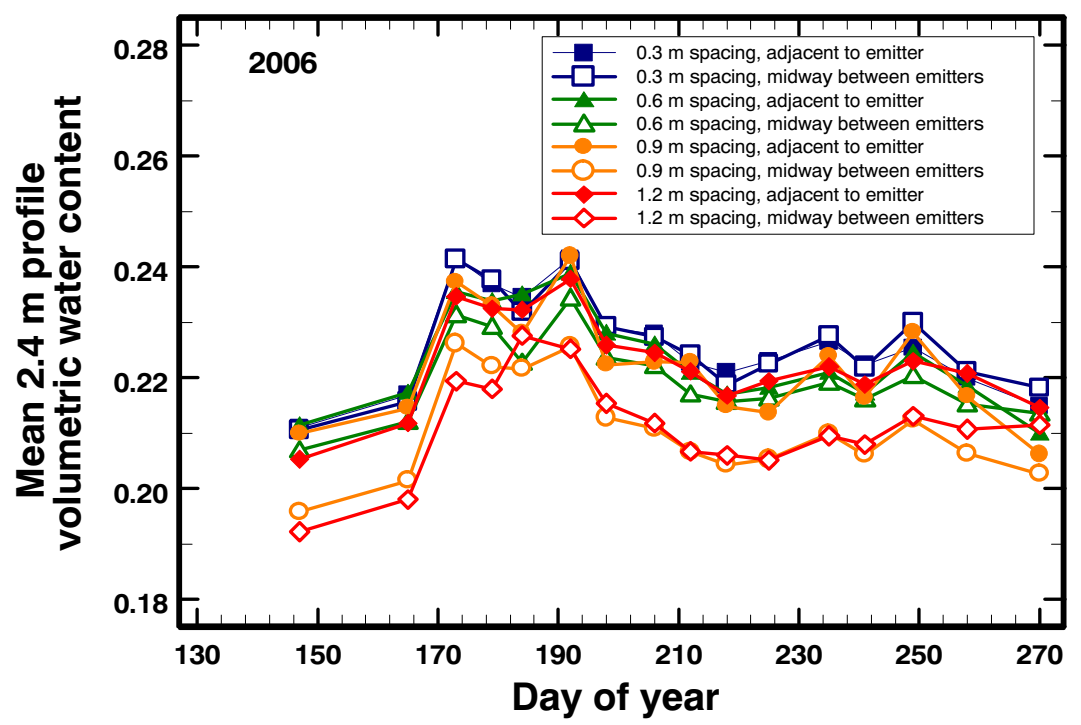

Figure 5. Mean volumetric soil water content for a $2.40-\mathrm{m}$ soil profile for corn in 2006 as affected by emitter spacing at sampling locations adjacent to the emitter and at the midway point between emitters.

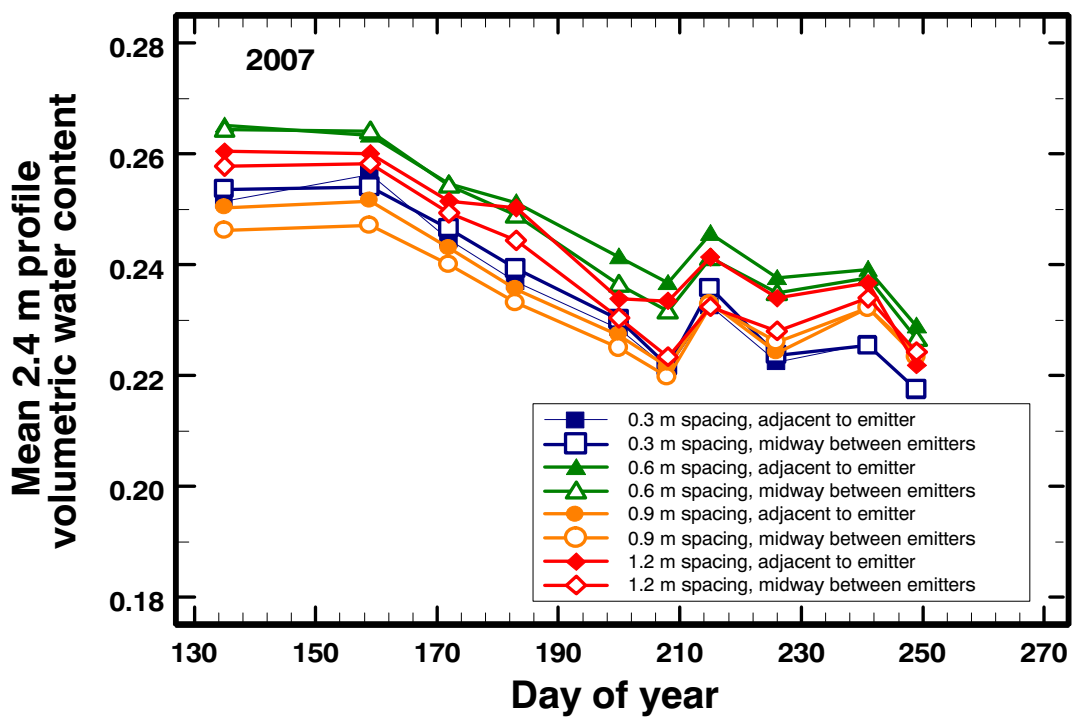

Figure 6. Mean volumetric soil water content for a 2.40 -m soil profile for corn in 2007 as affected by emitter spacing at sampling locations adjacent to the emitter and at the midway point between emitters. 


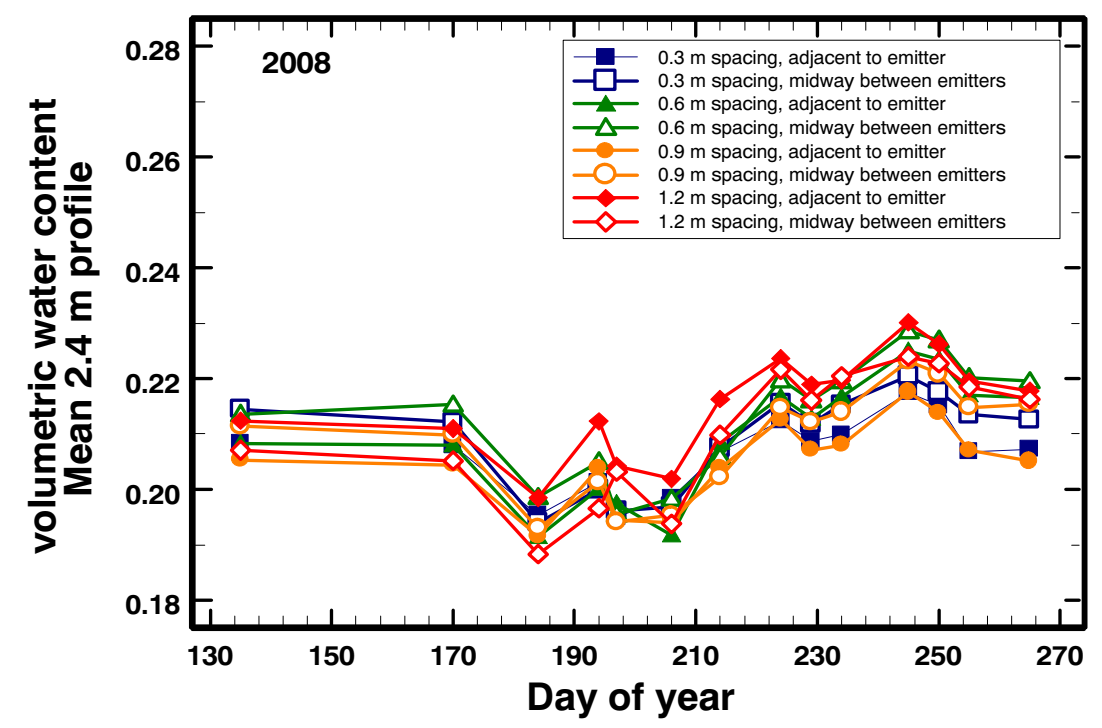

Figure 7. Mean volumetric soil water content for a $2.40-\mathrm{m}$ soil profile for corn in 2008 as affected by emitter spacing at sampling locations adjacent to the emitter and at the midway point between emitters.

\begin{tabular}{|c|c|c|c|c|}
\hline \multirow[b]{2}{*}{ Year } & \multicolumn{4}{|c|}{ Emitter Spacing $(\mathrm{m})^{[\mathrm{a}]}$} \\
\hline & 0.3 & 0.6 & 0.9 & 1.2 \\
\hline 2006 & $0.226 \mathrm{a}$ & $0.222 \mathrm{~b}$ & $0.216 \mathrm{c}$ & $0.217 \mathrm{c}$ \\
\hline 2007 & $0.234 \mathrm{~b}$ & $0.245 \mathrm{a}$ & $0.233 \mathrm{~b}$ & $0.240 \mathrm{a}$ \\
\hline 2008 & $0.208 \mathrm{ab}$ & $0.211 \mathrm{ab}$ & $0.207 \mathrm{~b}$ & $0.213 \mathrm{a}$ \\
\hline All 3 years & $0.222 \mathrm{a}$ & $0.224 \mathrm{a}$ & $0.217 \mathrm{~b}$ & $0.221 \mathrm{a}$ \\
\hline
\end{tabular}

[a] Emitter spacing means (the table rows) that are followed by different letters are significantly different at $\mathrm{P}<0.05$.

are not provided in this article. However, there were no significant differences between seasonal sampling dates in 2006 and 2008 and only minor differences for 2 July and 19 July in 2007. There were significant differences between emitter spacings when averaged over the whole cropping season (table 3) in each year, but from a practical standpoint these differences were negligible at less than 0.012 for any year.

It should be noted that the irrigation amount used in this study $(50 \mathrm{~mm} / \mathrm{event})$ during the cropping seasons could have an effect on the results. Irrigation events of this amount at the nominal emitter discharge would require approximately 35 , 69, 104, and $138 \mathrm{~h}$ to complete for the 0.3-, 0.6-, 0.9-, and $1.2-\mathrm{m}$ emitter spacings, respectively. Additionally, for the wider emitter spacings the wetted bulb would need to increase over those for smaller emitter spacings to redistribute the water. The results could conceivably be quite different for smaller irrigation amounts. On some soil types, irrigation event amounts as large as $50 \mathrm{~mm}$ might result in considerable amounts of deep percolation, but that did not appear to be the case in this study.

\section{Corn Yield, Yield Components, WATER USE, AND Water Productivity}

Corn grain yields ranged from 14.8 to $16.9 \mathrm{Mg}$ /ha during the three years of the study (table 4) and were considerably greater than typical commercial production of 12 to $13 \mathrm{Mg} / \mathrm{ha}$
(Lamm and Trooien, 2005). There were no significant differences in yields attributable to emitter spacing in any of the years. In fact, in 2006 and 2007 yield tended to be slightly greater for the wider spacings, but this tendency was not observed in 2008. The lack of corn yield reduction for the wider emitter spacings is probably attributable to the apparent increased preferential flow along the dripline and also to the buffering effects of summer rainfall and good water holding capacity discussed in the previous section.

There were generally no significant differences in any of the yield components with the exception of 2007 where the $1.2-\mathrm{m}$ emitter spacing had greater ear length than the $0.3-$ and $0.6-\mathrm{m}$ emitter spacings.

Seasonal corn water use and WP were not significantly affected by emitter spacing in any of the three years. The WP values were similar to those obtained in other corn field studies from this location (Lamm et al., 1997; Lamm and Trooien, 2005). These consistently large water productivities obtained in this study are further evidence that emitter spacings ranging from 0.3 to $1.2 \mathrm{~m}$ are probably acceptable on this soil type and climate for corn production when the crop is fully irrigated.

\section{Summary ANd CONClusions}

Increased soil water content in directions parallel to the dripline as compared to perpendicular, following non-cropped irrigation events 8 months apart, are indicative of increased preferential flow along SDI driplines or overlapping of the wetting zones of adjacent emitters. The fact that there were little or only minor differences in volumetric water contents adjacent to the emitter and at the midway point between emitters for emitter spacings ranging from 0.3 to $1.2 \mathrm{~m}$ during the course of three crop years provide further evidence of this preferential flow. There were no differences in corn grain yield or water productivity which suggests that under full irrigation this range of emitter spacings $(0.3$ to $1.2 \mathrm{~m})$ is acceptable. Summer precipitation and good water holding capacity for this deep, silt loam soil may be buffering differences that would likely occur between 
Table 4. Corn grain yield, yield components, season water use, and water productivity as affected by SDI emitter spacing (KSU-NWREC, Colby, Kans., 2006-2008).

\begin{tabular}{|c|c|c|c|c|c|c|c|c|c|}
\hline $\begin{array}{c}\text { Emitter Spacing } \\
(\mathrm{m})\end{array}$ & $\begin{array}{c}\text { Corn Yield } \\
(\mathrm{Mg} / \mathrm{ha})\end{array}$ & $\begin{array}{c}\text { Plant Density } \\
\text { (plants/ha) }\end{array}$ & Ears/plant & Kernels/ear & $\begin{array}{l}\text { Kernel Mass } \\
\quad(\mathrm{mg})\end{array}$ & $\begin{array}{l}\text { Water Use } \\
\quad(\mathrm{mm})\end{array}$ & $\begin{array}{c}\text { WP } \\
\text { (Mg/ha-mm) }\end{array}$ & $\begin{array}{l}\text { Ear Length } \\
\text { Rows[a] }\end{array}$ & $\begin{array}{c}\text { Ear Girth } \\
\text { Rows }\end{array}$ \\
\hline \multicolumn{10}{|c|}{ Crop Year, 2006} \\
\hline 0.3 & 15.2 & 85956 & 0.98 & 478 & 37.6 & 597 & 0.0255 & 31.4 & 15.1 \\
\hline 0.6 & 15.1 & 87111 & 0.98 & 465 & 38.0 & 604 & 0.0251 & 30.5 & 15.0 \\
\hline 0.9 & 15.8 & 91749 & 0.96 & 470 & 38.1 & 607 & 0.0260 & 30.9 & 14.9 \\
\hline 1.2 & 15.8 & 91813 & 0.98 & 465 & 37.5 & 576 & 0.0275 & 30.1 & 15.3 \\
\hline Mean & 15.5 & 89157 & 0.98 & 470 & 37.8 & 596 & 0.0260 & 30.7 & 15.1 \\
\hline \multicolumn{10}{|c|}{ Crop Year, 2007} \\
\hline 0.3 & 14.5 & 91562 & 1.01 & 557 & 28.3 & 556 & 0.0263 & $34.6 \mathrm{~b}$ & 16.0 \\
\hline 0.6 & 15.2 & 93436 & 1.00 & 556 & 29.6 & 560 & 0.0272 & $34.9 \mathrm{~b}$ & 15.9 \\
\hline 0.9 & 14.8 & 93936 & 0.98 & 568 & 28.1 & 530 & 0.0279 & $35.5 \mathrm{ab}$ & 16.0 \\
\hline 1.2 & 15.8 & 91125 & 0.99 & 595 & 29.6 & 558 & 0.0284 & $37.3 \mathrm{a}$ & 16.0 \\
\hline Mean & 15.1 & 92515 & 1.00 & 569 & 28.9 & 551 & 0.0274 & 35.6 & 16.0 \\
\hline \multicolumn{10}{|c|}{ Crop Year, 2008} \\
\hline 0.3 & 15.8 & 97747 & 1.00 & 508 & 32.0 & 673 & 0.0235 & 32.1 & 15.7 \\
\hline 0.6 & 16.8 & 95726 & 0.98 & 549 & 32.4 & 652 & 0.0257 & 34.6 & 15.8 \\
\hline 0.9 & 16.9 & 97062 & 1.00 & 534 & 32.7 & 665 & 0.0255 & 33.1 & 16.0 \\
\hline 1.2 & 15.2 & 97785 & 0.99 & 491 & 31.9 & 651 & 0.0233 & 31.4 & 15.6 \\
\hline Mean & 16.2 & 97080 & 0.99 & 520 & 32.2 & 660 & 0.0245 & 32.8 & 15.8 \\
\hline \multicolumn{10}{|c|}{ All Years } \\
\hline 0.3 & 15.2 & 91755 & 1.00 & 514 & 32.6 & 609 & 0.0251 & 32.7 & 15.6 \\
\hline 0.6 & 15.7 & 92091 & 0.99 & 523 & 33.3 & 605 & 0.0260 & 33.3 & 15.6 \\
\hline 0.9 & 15.8 & 94249 & 0.98 & 524 & 33.0 & 601 & 0.0265 & 33.2 & 15.7 \\
\hline 1.2 & 15.6 & 93574 & 0.99 & 517 & 33.0 & 595 & 0.0264 & 32.9 & 15.6 \\
\hline Mean & 15.6 & 92917 & 0.99 & 520 & 33.0 & 602 & 0.0260 & 33.0 & 15.6 \\
\hline
\end{tabular}

[a] Means followed by different letters are significantly different at $\mathrm{P}<0.05$ probability level.

emitter spacings in drier summer climates and on coarser, sandier soils. Additional caveats to these results are that corn is a deep and extensively rooted crop that can explore a large zone within the soil and the large irrigation event amount $(50 \mathrm{~mm})$ used in this study would probably be beneficial for the wider spacings provided that deep percolation was minimized.

Further research at this site is being conducted to examine the effects of a smaller irrigation event amount (13 to $25 \mathrm{~mm} / \mathrm{event})$ under slightly deficit irrigation $(75 \%$ of full irrigation) on corn production. Additional studies might examine shallow-rooted or tap-rooted crops that may not be able to explore as large a soil profile as corn.

\section{ACKNOWLEDGEMENTS}

This is a joint contribution of the University of Girona, Girona, Spain and Kansas State University, Manhattan, Kansas. Contribution No. 10-108-J from the Kansas Agricultural Experiment Station. This article is part of a two-year SDI technology transfer effort that began in 2009 involving Kansas State University, Texas A\&M University and the USDA-ARS and is funded by the Ogallala Aquifer Project.

\section{REFERENCES}

Allen, R. G., L .S. Pereira, D. Raes, and M. Smith. 1998. Crop evapotranspiration, guidelines for computing crop water requirements. FAO Irrig. and Drain. Paper 56. Rome, Italy: Food and Agric. Organ. United Nations.

Battam, M., S. Robinson, and B. Sutton. 2002. Water surfacing from subsurface drip emitters. In Proc. Irrig. Assoc. Australia, 277-281. Hornsby, Australia: Irrigation Australia.

Battam, M. A., B. G. Sutton, and D. G. Boughton. 2003. Soil pits as a simple design aid for subsurface drip irrigation systems. Irrig. Sci. 22(3): 135-141.

Bidwell, O. W., E. E. Banbury, W. L. Barker, and G. E. Muilenburg. 1980. The Colby Branch Experiment Station and agriculture in northwest Kansas with special mention of soils. KAES Bulletin 635. Manhattan, Kans.: Kansas Agric. Expt. Sta.

Camp, C. R. 1998. Subsurface drip irrigation: A review. Trans. ASAE 41(5): 1353-1367.

Howell, T. A. 2007. Personal communication concerning alfalfa-based reference evapotranspiration. 19 April 2007.

Jensen, M. E. 1969. Scheduling irrigation using computers. J. Soil and Water Cons. 24(8): 193-195.

Jensen, M. E., C. E. Franzoy, and D. C. N. Robb. 1970. Scheduling irrigations using climate-crop-soil data. ASCE, J. Irrig. and Drain. 96(IRI): 25-38.

Jensen, M. E., B. J. Pratt, and J. L. Wright. 1971. Estimating soil and moisture depletion from climate, crop and soil data. Trans. ASAE 14(5): 954-959.

Kincaid, D. E., and D. F. Heerman. 1974. Scheduling irrigation using a programmable calculator. USDA Publication ARS-NC-12. Washington, D.C.: USDA. 
Lamm, F. R., and A. A. Abou Kheira. 2009. Corn irrigation macromanagement at the seasonal boundaries: Initiating and terminating the irrigation season. In Proc. Central Plains Irrigation Conf., Colby, Kans. Available from CPIA, $760 \mathrm{~N}$. Thompson, Colby, Kans., pp. 40-60. Also at: http://www.ksre. ksu.edu/sdi/Reports/2009/Lamm09SB.pdf . Verified 20 April 2010.

Lamm, F. R., and C. R. Camp. 2007. Chapt. 13: Subsurface drip irrigation. In Microirrigation for Crop Production: Design, Operation and Management, 473-551. F. R. Lamm, J. E. Ayars, and F. S. Nakayama, eds. Amsterdam, The Netherlands: Elsevier Publications.

Lamm, F. R., and D. H. Rogers. 1983. Scheduling irrigation using computed evapotranspiration. ASAE Paper No. MCR 83-109. St. Joseph, Mich.: ASAE.

Lamm, F. R., and D. H. Rogers. 1985. Corn yield response to different irrigation regimes. ASAE Paper No. MCR 85-131. St. Joseph, Mich.: ASAE.

Lamm, F. R., and T. P. Trooien. 2003. Subsurface drip irrigation for corn production: A review of 10 years of research in Kansas. Irrig. Sci. 22(3-4): 195-200.

Lamm, F. R., and T. P. Trooien. 2005. Dripline depth effects on corn production when crop establishment is nonlimiting. Appl. Eng. in Agric. 21(5): 835-840.

Lamm, F. R., D. A. Pacey, and H. L. Manges. 1987. Spreadsheet templates for the calculation of Penman reference evapotranspiration. ASAE Paper No. MCR 87-106. St. Joseph, Mich.: ASAE.

Lamm, F. R., L. R. Stone, H. L. Manges, and D. M. O’Brien. 1997. Optimum lateral spacing for subsurface drip-irrigated corn. Trans. ASAE 40(4): 1021-1027.

Lazarovitch, N., J. Simunek, and U. Shani. 2005. System dependent boundary condition for water flow from subsurface source. Soil Sci. Soc. America J. 69(1): 46-50.
Seginer, I. 1979. Irrigation Uniformity related to horizontal extent of root zone. Irrig. Sci. 1(2): 89-96.

Schwankl, L. J., and B. R. Hanson. 2007. Chapt. 12: Surface drip irrigation. In Microirrigation for Crop Production: Design, Operation and Management, 431-472. F. R. Lamm, J. E. Ayars, and F. S. Nakayama, eds. . Amsterdam, The Netherlands: Elsevier Publications.

Schwartzman, M., and B. Zur. 1986. Emitter spacing and geometry of wetted soil volume. ASCE J. Irrig. Drain. Eng. 112(3): 242-253.

Shani, U., S. Xue, R. Gordin-Katz, and A. W. Warrick. 1996. Soil-limiting flow from subsurface emitters: I. Pressure measurements. ASCE J. Irrig. Drain. Eng. 122(5): 291-295.

Singh, D. K., T. B. S. Rajput, D. K. Singh, H. S. Sikarwar, R. N. Sahoo, and T. Ahmad. 2006. Simulation of soil wetting pattern with subsurface drip irrigation from line source. Agric. Water Mgmt. 83(1-2): 130-134.

Thorburn, P. J., F. J. Cook, and K. L. Bristow. 2003. Soil-dependent wetting from trickle emitters: Implications for system design and management. Irrig. Sci. 22(3): 121-127.

Warrick, A. W., and U. Shani. 1996. Soil-limiting flow from subsurface emitters: II. Effect on uniformity. ASCE J. Irrig. Drain. Eng. 122(5): 296-300.

Warrick, A. W., and D. Or. 2007. Chapt. 2: Soil water concepts. In Microirrigation for Crop Production: Design, Operation and Management, 27-59. F. R. Lamm, J. E. Ayars, and F. S. Nakayama, eds. . Amsterdam, The Netherlands: Elsevier Publications. 
